\title{
Intelligent Textiles and its applications: An overview
}

Satish Khatak

Department of ECE, The Technological Institute of Textile \& Sciences, Bhiwani-127021(Haryana)

To Cite this Article

Satish Khatak, "Intelligent Textiles and its applications: An overview", International Journal for Modern Trends in Science and Technology, 6(9S): 68-71, 2020.

Article Info

Received on 25-August-2020, Revised on 08-September-2020, Accepted on 12-September-2020, Published on 18-September-2020.

\section{ABSTRACT}

Intelligent wearable clothing can be seen as textiles that possess the capability of sensing and responding to environmental changes. The clothing sense the physical activity of the person and his environment, monitor and analyze it, and accordingly attempts to respond in most appropriate manner. Intelligent textiles are laced with embedded electronics sensors and other circuitry into fabric thereby resulting in smart outfits capable of an array of diverse applications. Intelligent textiles find applications in defense sectors, railways, firefighters, police, skydivers, sports-persons and other professional activities. The aim of this study is to highlight the protective applications of wearable intelligent textiles and their significance in the present context.

KEYWORDS: Intelligent, Textiles, Defense, Sensors, Smart, Technology.

\section{INTRODUCTION}

"Intelligent textiles" are fabrics that have been designed and developed with innovative technologies that offer added advantage to the wearer. They have the capability to sense, monitor, process information, analyze, and react accordingly. They may be wearable and also they have monitoring and computation, as well as wireless information transfer capabilities. Some sensors and other computational elements are embedded in intelligent textiles, as well as built into yarns, with the aim of collecting useful information, monitoring vital statistics, and transferring them remotely for further processing. Intelligent textiles can be broadly divided into two main categories as aesthetic textile and performance enhancing textiles. The examples of aesthetic textile include fabrics that glow and fabrics that can alter colour. These fabrics may collect energy from the environment by harnessing sensations, sound or heat, reacting to these inputs.
Also the colour changing and lighting scheme can also work by embedding the fabric with electronic battery or cell that can power it. On the other hand Performance enhancing intelligent textiles are proposed for use in athletic, extreme sports, military and other such applications. They are designed to regulate body temperature and blood pressure of the wearer, decrease wind resistance, and control muscle vibration and these results in improved athletic performance. Other intelligent fabrics have also been developed for protective clothing, to guard against extreme hazardous environmental conditions, such as radiation and the effects of space travel, to safeguard firefighters against fire and heat etc. The other sectors such as health and beauty industry are getting benefits of these innovations, which range from drug-releasing medical textiles, to fabric with moisturizer, perfume, and anti-aging properties. In case of electronic textiles the emphasis is given on the flawless integration of textiles with 
electronic elements like microcontrollers, sensors, and actuators or any other active or passive components. Also they may be wearable or non-wearable as there are electronics textiles which found application in interior design. The challenging side for embedding electronic function in the clothing are flexibility, life, lightweight, comfort-level, conductivity, good process ability, good wear ability and cost effective. The research in this field is growing so rapidly that with new technologies we can integrate several electronic devices directly into textile \& apparel products using common resources enhancing the mobility, comfort \& convenience of such device to a great extent.

\section{WORKING PRINICPLE}

When we talk about intelligent Textile it is having some advance features as compared to the smart textile. As smart textile senses the environment the intelligent textiles also have the capability to sense parameters from the environment but along with that they analyze and process it, and respond accordingly. So we can say that intelligent textiles have to perform some basic functions to complete its task. These are

1. Sensors:-With the help of sensors it is going to gather some parameters heat, temperature, pressure velocity etc from the environment. These sensors should have very high sensitivity and accuracy .They should also have small size and light in weight.

2. Processing, Monitoring and Analyzing Unit:-With the help of this section the intelligent textile is going to make an appropriate decision as per the stimulation and some predetermined data. It may contain microcontroller units and other electronic circuitry

3. Actuators.:- This is the unit which gives response as per the stimulation captured by the sensors

Apart from these, if we want to transfer the vital information or data to a remote location for further monitoring, controlling and recording purpose we may require some more electronic circuitry.

\section{DEVELOPMENTAL STAGES OF INTELLIGENT TEXTILES}

Functionally the development can be understood as follows-

1. Passive smart Textiles:-These are composed of devices or materials which are going to sense the environment. They are basically having sensor only, which respond the stimulus by showing change in electric or thermal resistance, colour, shape etc. The best example is dresses which have inbuilt thermistors to $\log$ body temperature over the time.

2. Active Smart Textiles: - These not only senses the external environment condition but also respond to it. In these actuator is there which respond to a particular stimulus from the environment. We are having temperature sensing shirts which rolls up the sleeves if the body temperature rises beyond some predetermined values.

3. Intelligent Textile:-These are having capability to sense, react and adapt accordingly.

4. Textile integrated with Artificial Intelligence:-If these extra smart textiles are embedded with artificial intelligence, than they reach at next higher level of intelligence. They can than analyze more smartly and make decisions of their own like human beings, by means of virtual mind.

\section{APPLICATION AREAS}

1. Sports Activities:-The intelligent Textiles with the aim to improve performance of sports person and personal comfort, plays a very crucial role. A smart sock with a foot pressure measurement technology and walking distance measurement that can be used to measure sports performance. The various electronic parts of this product can be separated in order to clean and wash the textile part of the socks. The collected data is sent wirelessly to a mobile application running into a Smartphone. With this intelligent device, the athletes can see and monitor the pressure profile of the foot sole and then practice their gait cycle to achieve a better performance. A sports person can wear intelligent bands, jackets, caps to continuously monitor the pulse rate, blood pressure, body temperature, fatigue. The necessary data can be sent to remote location where it can be analyzed and may be used to improve the performance of the sports person. Similar types of devices can be used by sky divers, swimmers or other sports persons to monitor, analyze and improve their performance. $[1,3]$

2. Health sector:-Smart and Intelligent textiles which are being utilized by health care industry are proving to be a boon to this sector. Intelligent wearable textile which are basically composed of various embedded sensors, actuators, microcontrollers which not only senses, register, monitor and analyze the physical and mental health of the person but it also transmit the 
necessary data from the patient to the medical expert.

There are diverse applications in medical sectors where these electronic or intelligent textiles are extensively used. To ease the symptoms of Seasonal Affective Disorder (SAD), electro-luminescent wire being explored by creating bedding that emits light. Intelligent bras are there which have the capability to detect symptoms of breast cancer at an early stage so that iit can be treated and cured. For the monitoring of respiration system, Heart pumping system, and other physical activity, various wireless enabled intelligent garments have been developed and still some are in pipeline. These are going to be very helpful for the persons who are prone to heart attack as these wearable intelligent textiles will detect the early signs and warn the wearer and simultaneously sent the data to the person who is monitoring such a person. Intelligent shirts are also developed in which the conductive fibers and various sensors are embedded which measures and monitor respiration system. The "tricoder for babies" are there which tracks vital as well as changes in body temperature. The increasing demand of these wearable intelligent textiles from health care sector is going to help in developing more advance types of such intelligent textiles embedded with artificial intelligence.[6]

\section{Military and Defense sector}

Due to technological advancement in electronic sector it is now possible to develop very small sized electronics devices which can be embedded in textiles and can be used in defense sector. This will give new dimensions to military and defense security. In adverse environmental conditions and hazardous situations faced by soldiers, there is a need of real time information system to give protection and survivability to them. This will help in improving performance and other capabilities of the defense forces and emergency response services. The requirements for such situations are to monitor vital signs and ease injuries while also monitoring environment hazards such as toxic gases. The intelligent textile in military can be utilized in two ways. Firstly, Personal protective garments and individual equipments which includes battle uniforms, ballistic protection vests and helmets, chemical protection suits, belts, ropes, suspenders and field-packs. Secondly, defense systems and weapons like parachutes, shelters tent houses etc. The enhanced security to both these can be provided with intelligent textiles. If a soldier get injured during war or any other situation and he is wearing an Intelligent jackets than this information is automatically transferred to the nearby controlling and monitoring unit and necessary medical or any other help can be provided to the injured soldier. The soldier can himself monitor his pulse rate, blood pressure and other parameters through the embedded intelligent systems in the jacket. Intelligent materials are being developed to equip the army of future with uniforms which help in heal, shield, and protect them against chemical and biological warfare[2]. The work is also going on to develop such a uniform that is almost invisible and soft clothing that can become a rigid cast when a soldier break his or her leg. Also with the help of sensors in jacket he can monitor his surroundings. So this combination of electronics and textile will largely benefit the defense personals. No doubt much more is need to done to develop best possible intelligent protective wearable textiles in this sector. $[5,7]$

\section{Safety purpose}

Intelligent jackets and shirts especially for the protection of public safety personnel, namely firefighters, rescue teams, police officers are being developed with all necessary advanced safety features. They will be used in conjunction with a wireless- enabled radio system. The intelligent jacket or shirt can monitor the health and safety of public safety personnel, victims trapped in a building or underneath rubble with the ability to detect the exact location of the victims through positioning capability. In addition to monitoring vital signs, the system can detect the extent of falls, and the presence of harmful gases. It can also facilitate two- way voice and video communication. An integration of sensors and flexible light emitting displays with textile can help in designing a wearable warning signal generating jacket. This can receive and respond to stimuli from body, enabling a warning signal to be displayed and sent. The sensors in the jacket keeps on monitoring the vital body parameters and if something unusual happens, same is indicated through flash of light and a wireless communication system could send a distress signal to a remote location. Textiles integrated with electronic sensory devices driven by global positioning system can detect one's exact location anytime and in any weather. Fabric area networks (FANs) make it possible with the help of electronic devices to exchange required information, power and control signals within the user's personal space and remote locations[8].

\section{Fashion and Lifestyle}


The development of high tech intelligent textiles for initial high-value applications such as extreme sports will eventually find its way into street fashion. There are fabrics with moisture management systems being used for fast evaporation of sweat. Fabrics with UV protection, anti allergic and anti bacterial capabilities are available. There are intelligent dresses and sleep suit which emits scents depending on your mood and requirement. Intelligent fibers are being developed that can change colour and its shape as per your command. The conductive fibers could change colour on command from an electric signal that alters the reflective quality of this special fiber. Thereby increasing function as well as fashion. Intelligent Textile with thermoregulation properties are also being developed. These textiles contain phase change materials which react immediately with change in surrounding temperatures, and the temperature in different parts of the body. When there is a rise in temperature, the phase changing material microcapsules react by absorbing heat and storing this energy in the liquefied phase change materials. When temperature falls again, the microcapsules release this stored heat energy and the phase change material solidify again. There are also interactive fibers which incorporates electronics that are activated by a power source[4]. There are wearable electronics which can be used in intelligent wearable textiles to dial mobile numbers, control music from $\mathrm{mp} 3$ player etc. The examples includes business suit with a mobile phone incorporated, sportswear to monitor heart rate, aerobic outfits with music players incorporated and club wear which changes colour. This is only being possible because of integration of electronics and textiles. $[9,10]$

\section{FUTURE PROSPECTS}

In the coming years the fibertronics will become advanced and in such situation all the electronic functions such as computing, fast and reliable communication, power sources, etc are embedded in fifer itself. The nano-technology will give new horizons to the intelligent textiles. Embedded optical fiber and micro-porous breathable fabrics will be more effectively and efficiently utilized in development of intelligent textiles. Weather proof and water proof systems needs to be developed. Lots of improvements are still needed in current technologies to make it more reliable, authentic, durable and economical so that it will reach to every corners of life of a common man.

\section{CONCLUSION}

This paper summarizes the main concept of Intelligent Textiles and its some of the current and future possible applications. Due to advancement in electronics, the devices are becoming smaller and smaller and it is becoming easier to integrate them with the fibers. The current technological shortcoming will be removed very soon in the coming years and more reliable, high performance and efficient intelligent textile devices will be available in future.

\section{REFERENCES}

[1]. "Wearable sensors for Human Activity Monitoring: A Review". S.C.Mukhopadhyay, Massey University on March 2015.

[2]. "A Review of smart Clothing in Military", Sofiascataglini, Johan Gallant and Giuseppe Andreoni, Conference paper on May 2015.

[3]. "Wearable Electronics and Smart Textiles: A Critical Review", MatteoStoppa Alessandro Chiolerio, Center for Space Human Robotics, Istituto Italiano di Tecnologia, Corso Trento 21, 10129 Torino, Italy. Received: 14 May 2014; in revised form: 2

[4]. "Applications of Smart and Interactive Textiles". Textile Learner. Saddamhusen Jamadar. Archived from the original on 2013-06-12.Retrieved 2013-04-21.

[5]. "Smart Shirt." Wikipedia. Wikimedia Foundation, 22 Aug.2012. Web. 07 Oct. 2012. <http://en.wikipedia. org/ wiki/ Smart_shirt>

[6]. "Smart textiles for healthcare: applications and technologies",Viktorija Mečñika1 Ms.sc.; Melanie Hoerr2 Dipl.-Ing.; Ivars Krievinsš1 Assoc.prof. Dr.sc.ing.; Anne Schwarz2 Dr.sc.ing.

Institute of Textile Technology and Design of Riga Technical University, Latvia1; Institutfuer Textiltechnik of RWTH Aachen University, Germany2 viktorija.mecnika@rtu.lv, ivars. Krievins @rtu.lv1; melanie.hoerr@ita.rwth-aachen.de, anne.schwarz@ ita. rwth-aachen.de2

[7].http://www.army.mil/article/133577/Body_sensors_to_hel p_Soldiers_in_future_conflicts

[8]. "Electronic Textiles: Fiber- Embedded Electrolyte -Gated Field-Effect Transistors for e-Textiles", Hamedi, M.; Herlogsson, L.; Crispin, X.; Marcilla, R.; Berggren, M.; Inganäs, O. $(22$ January 2009). Advanced Materials.John Wiley \& Sons, Inc. doi:10.1002/adma.200990013.PMID 21162140 - via Wiley Online Library.

[9]. "Smart Fabrics and Interactive Textile Enabling Wearable Personal Applications: R\&D States of the Art and Future Challenges", A.Lymberis, R.Paradiso, 30th Annual International IEEE EMBS conference, Vancouver, British Columbia, Canada, August 20-24, 2008.

[10]. "Interactive electronic textile development" Dina Meoli and Traci May-plumle; Journal of Textile and Apparel, Technology and Management; Volume 2(2), Spring 2002. 